A major purpose or the I ecnnical Information Center is to provide the broadest dissemination possible of information contained in DOE's Research and Development Reports to business, industry, the academic community, and federal, state and local governments.

Although a small portion of this report is not reproducible, it is being made available to expedite the availability of information on the research discussed herein. 


\section{DISXI.AIMER}

This repurt was prepured un an actount of work spenmured by an agency of the IInited Silates (invernment Neither the I/niled Sintes (invernneent nor uny agency thereul, mur uny of their empluyees, maken any warranty, express or inuplied, or unumes any legal limbilisy or reaponahalily for the accuracy, completenesw, or usefulness of any informution, apparatus, product, or

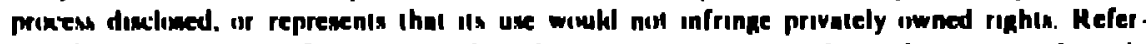

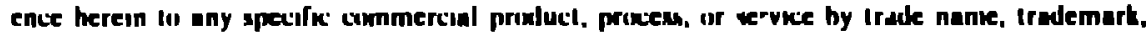
manulaclurer, of itherwie does nos necesunrily connalitule is iniply its endorsentent, recom-

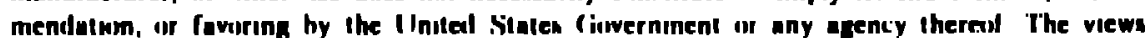

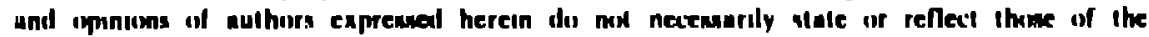
IInited siluten fiwernment of any apency there, 


\title{
A Tracking Rangefinder for Muons from Kaon Decay
}

\author{
J. Frank(a), G.W. Han, W.W. Kinnison, D.M. Lee, R.J. McKee, \\ E.C. Milner, G.H. Sanders, H.-J. Ziock. \\ Los Alamos National Laboratory, Los Alamos, New Mexico $875 \sqrt{5}$ \\ M. Chapman, M. Eckhause, J.F. Ginkel, P.P. Guss(b), D. Joyce(c), J.R. Kane, \\ C.J. Kenney, R.E. Welsh, R.J. Whyley(d), R. Winter, W.F. Vulcan, \\ College of William and Mary, Williamsburg, Virginia 23185
}

\begin{abstract}
A bstract
A muon rangefinder with tracking capabilities has been constructed as part of a search fer the rare decay $\mathrm{K}_{\mathrm{L}}^{0} \rightarrow$ we in experiment 791 at the Brookhaven National Laboratory Alternating Gradient Synchrotron. The rangefinder consisted of Iwo identical arms, symmetric p.tuut the beamline, and was the final detector elament in a spectrometer system. Each side of th. rangefinder was comprised of 75 slabs of marble and 25 slabs of aluminum, each $7.62 \mathrm{~cm}$ thick. covering an acceptance area $225 \mathrm{~cm}$ wide by 301 $\mathrm{cm}$ high, with a toul mass of 160 tons $(145,454$ $\mathrm{kg}$ ). There were 13 pairs of $x$ - and $y$-measuring proportional lube planes p-oviding a nomina! $\pm 10 \%$ accuracy measurement of muon momentum. Allogether, there were 11.648 sense wires. operating at $2650 \mathrm{~V}$, with equal parts argon (49.2\%) and ethane (49.2\%) gas, and a small amount (1.6\% of the total gas) of ethyl alcohol flowing in the proportional tubes. During 850 hours of data collection. efficiency averaged 94\%, with 160-ns drift time at $1.5 \mu \mathrm{A}$ threshold. For well-identified muon iracks. rangefinder muon identification was 90\% efficient wheh penetration to at leas! 60\% of the depth er yected from spectrometer-derived momentum was required.
\end{abstract}

In this repon, we describe a Iracking muon rangefinder used in the Brookhaven National Laboratory Alternating Gradient Synchrotson (ACS) experiment 79 (1) in positively identify muons in a search for the rare decay $K^{\prime \prime}, \rightarrow$. $\rightarrow$ The muon rangefincter was the final detector element in the apparatus shown in ligure 1 . The neutral kaun heam was produced by 24 ! (jeV protons striking a colper largel. Dipole magnels downstream of the target wept charged particles out of the beam into a stack of iron below the beamline. The extent of the neutral beam was defined by a series of collimators centered at 2.75 degrees from the incident proton-beam direction. At this production angle there were approximately three times as many neutrons as kaons in the beam. To minimize the rate of spurious hits arising from neutron interactions. the neuiral beam was transported through the apparatus in a helium-filled corridor.

The detector was a symmetric two-armed configuration surrounding the neutral beam. Lowmass, high-resolution drift chambers surrounding two spectrometer magnets were the first detector elements and were used 10 measure particle momenta. Trigger scintillator hodoscopes were placed both upstream and downstream of $\mathrm{N}_{2}$ - He gas Cherenkov counters. A Pb-glass array was used to perform electron and photon calorimetry. Particles which passed through a $91 \mathrm{~cm}$ iron filter and were detected in $x-y$ planes of scintilators were assigned a "muon probability" based on their proximity in space and time to tracks identified in the spectrometer. Finally, the track penetration depth in the rangefinder, which was correlated it) the original track momentum, was used (o) positively identify muons. Fivents with at least one track in each spectrometer arm, and a reconstrur:ted decay vertex within the vacuuln decay volume were accipled for offline nnalysis.

Design goals for the rangefinder arose from Monte Carlo studies indic ating that muon mornentum determination with approximalely tI0) nccuracy would provide information useful in an online fast elec(ronics calculation of haon mass for trigering purposes, and for musu ilenufication redundancy. To achieve this ponl.

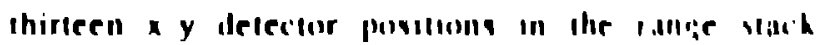
were siectified with Mo,ite ciallu slldies 


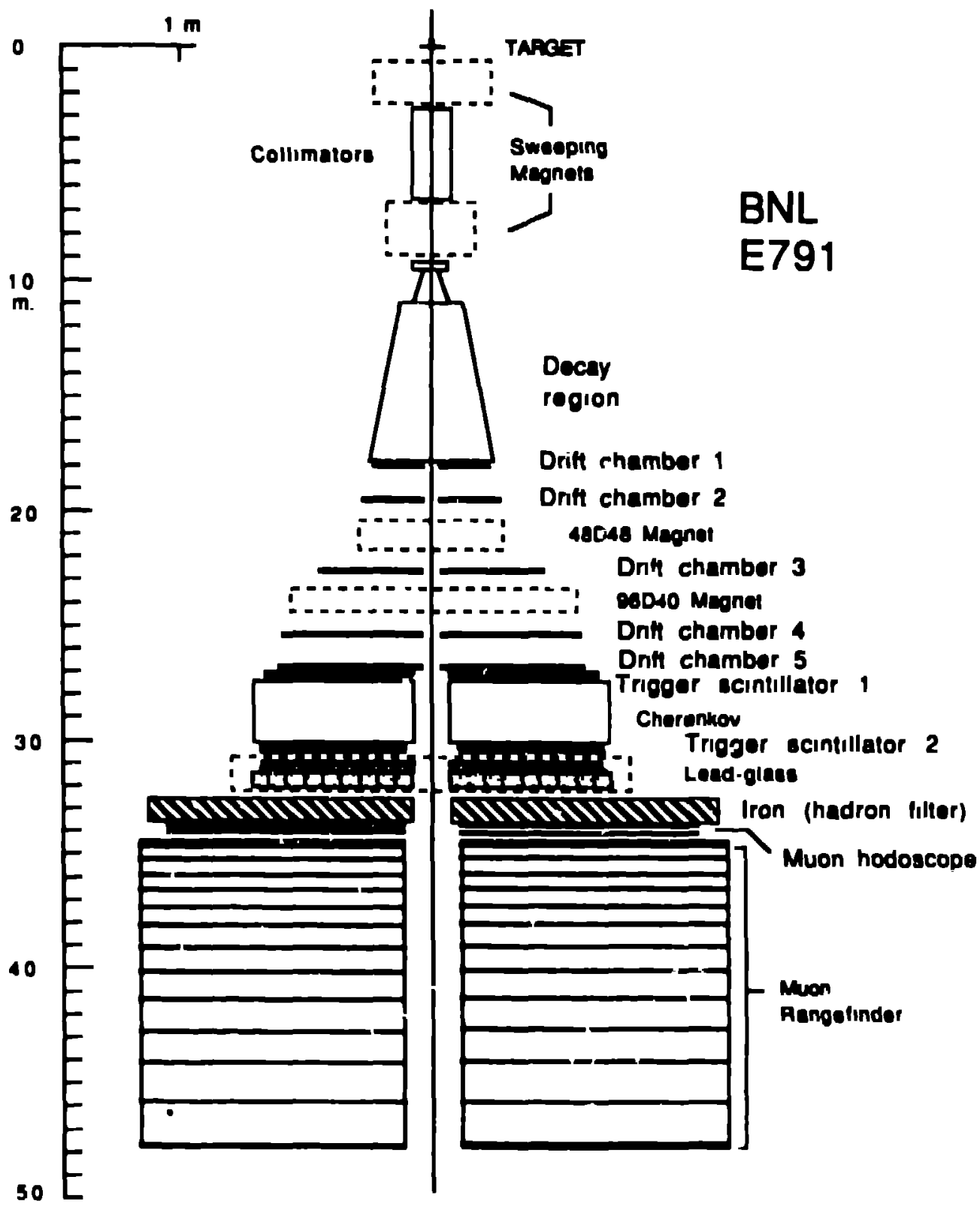

Eioure 1 Schematic viow of the detertor aystem. The diagram showe the plen viow and is drawn with the indicated vertical and horizontal scales The rangefinder dotector planes wore placad in the thinteen positions shown

The iwo syinmetric arms each consisied of 79 slabs of marhle followed by 25 iabs of aluminum, $7 \mathrm{e} 2 \mathrm{~cm}$ thick. $309 \mathrm{~cm}$ high and 244 im wide. to malch the geometrical accepiance of the uparean delector elementa in the experimenl The absorber was arranged with $(x)$ I $2 \mathrm{~cm}$ slahs and $10 \mathrm{~cm}$ gaps in each vide is) accommoxlate a planned upsiate( 2$)$ to full muon polarimeter capahility. in which all $2(x)$ papa winld be instrumented lin a varth for $\mu$ "

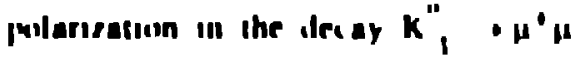

('onsideratuns related lo the future pularimalion measurement influenced reveral design choices For example, the 7 o2 in materual thickiness was specified heciause ihat is approximately opismum for detecting musn processional decay

asymmeiry Marhle and aluminum were used hecause they do not denraile stopped munn

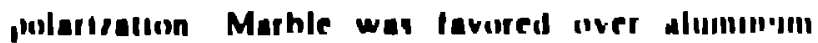
bracuse it was three imes less expensive and is lew sucepuble ti) neutrun aclivalion 


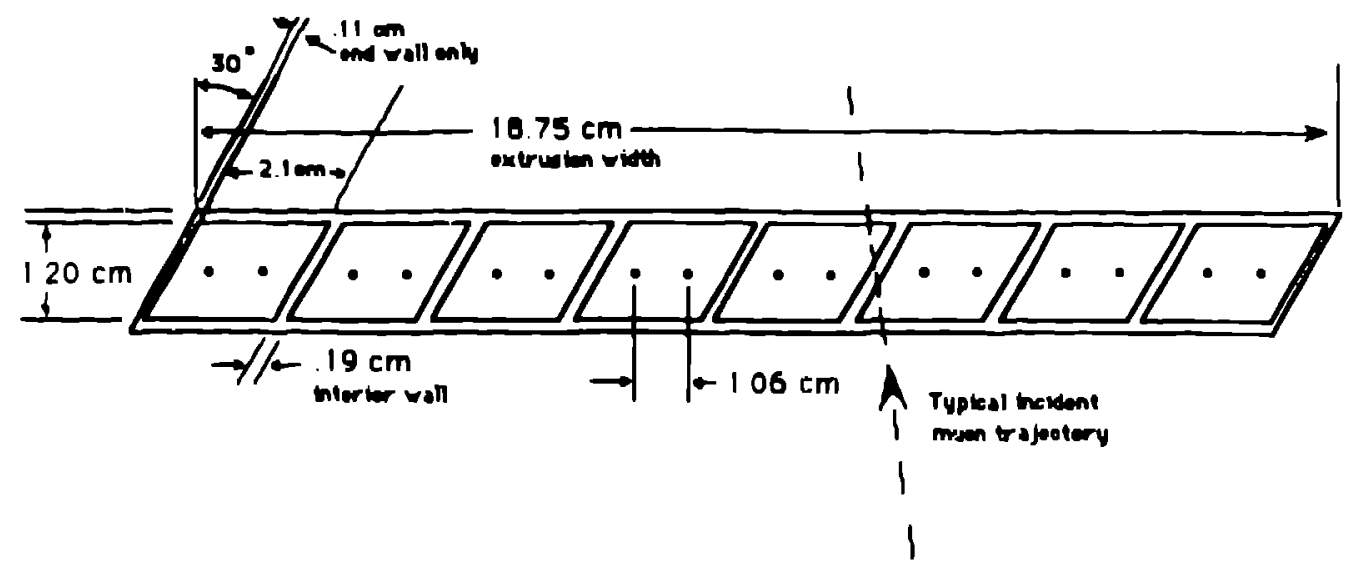

Eigure2 Cross-sectional drawing of a drift tube extrusion, showli.g the elght Indivlduel drift cells, and iwo sense wires in each coll Tha slented geometry of the cell increesed the amount of gas lonized by pertleles pessing near coll walls. The extrusion materlal was C063-T6 oluminum alloy Wires ware gold-pleted tungsten, 3 mils in diemeler, installed and lested to be under o tension of 500 groms.

The marble was quarried in Carrara, Italy and shipped to New York in $7.62 \mathrm{~cm} \times 112 \mathrm{~cm} \pi$ $150 \mathrm{~cm}$ pieces, the largesi commercially feasible size. One-hundred-fifty assemblies were fabricated by edge-gluing four marble pieces together with epoxy. and banding the slab with $0.63 \mathrm{~cm}$ thick stainless steel, to provide extra structural integrity required for moving them into place in the detector. Individual pieces of marble were placed on rolier-bearing lables, epoxy was applied, and bar-clamps were used to hold the assemblies together during the 8-hour epoxy curing-lime. Each assembled slab weighed approximately $14.55 \mathrm{~kg}$. The finished asseinbly was lified from the horizontal to vertical position by a crane allached to the steel band and transferred into place on the detector stand.

The detectors were proportional luhes operated with a yas consisting of equal parts argon (49.2\%) and ethane (49.2\%). and a small (1.6\%) amount of eihyl alcohol(3). There were Iwo sense wires in each cell, at a nominal volenge of $2650) \mathrm{V}$, with eight cells in each $19 \mathrm{~cm}$-wide aluminum exirusion. A crose-sectional drawing of the aluminum extrusion is shown in Figure 2. 'The cell geomelry wan designed to maximize efficiency by utilizing a parallelogram shape. so that iracts passing near inter cell walls would pass through a rufficient amcunt of gas 10 repister a hit The area of coverage in each arm was $2.9 \mathrm{~m} \mathrm{~m} 101 \mathrm{~m}$, w $x$-measuring planes were constructed by edgebonding with an anerobic adhesive 12 extrusions, $3.01 \mathrm{~m}$ long. and $y$-measuring planes were built from 16 extrusions, $2.25 \mathrm{~m}$ long (Figure 3), Each $y$-plane had 128 cells and 256 wires, while an $x$ plane had 96 cells and 192 wires. With $13 x$ - and $y$-measuring planes in each arm, the rangefinder therefore had 5,824 active cells, and 11,648 active sense wires. Wires were held in position by molded Lexan endcaps accommodaring Noryl chamber and stainless steel crimped minitube wireholderg(4). Two wires were installed in each cell to shorten the ionization collection lime. The wires were gold-plated lungsien. 3 mils $(7.5 \mu \mathrm{m})$ in diameter, with an elastic limit of $925 \mathrm{E}$. installed uniler 500-8 tension. Prior to final assembly of a complete plane, the tension on each wire was tested(5). A portion of the wite wav placed in a static magnetic field, while an oscillating voltage was applied to the wire. Voltake induced on the wire out-of phase with the applied volage peaked at the harmonics of the wire vibration. and was observed by inonitoring the shape of lissajous figures. The relation piving the iension was then $I=4 \mu l .^{2} r^{2}$, where $t$. is the length of the wire. $\mu$ is the wire linear mass densily, an!' $f$ is the vihration frequency 


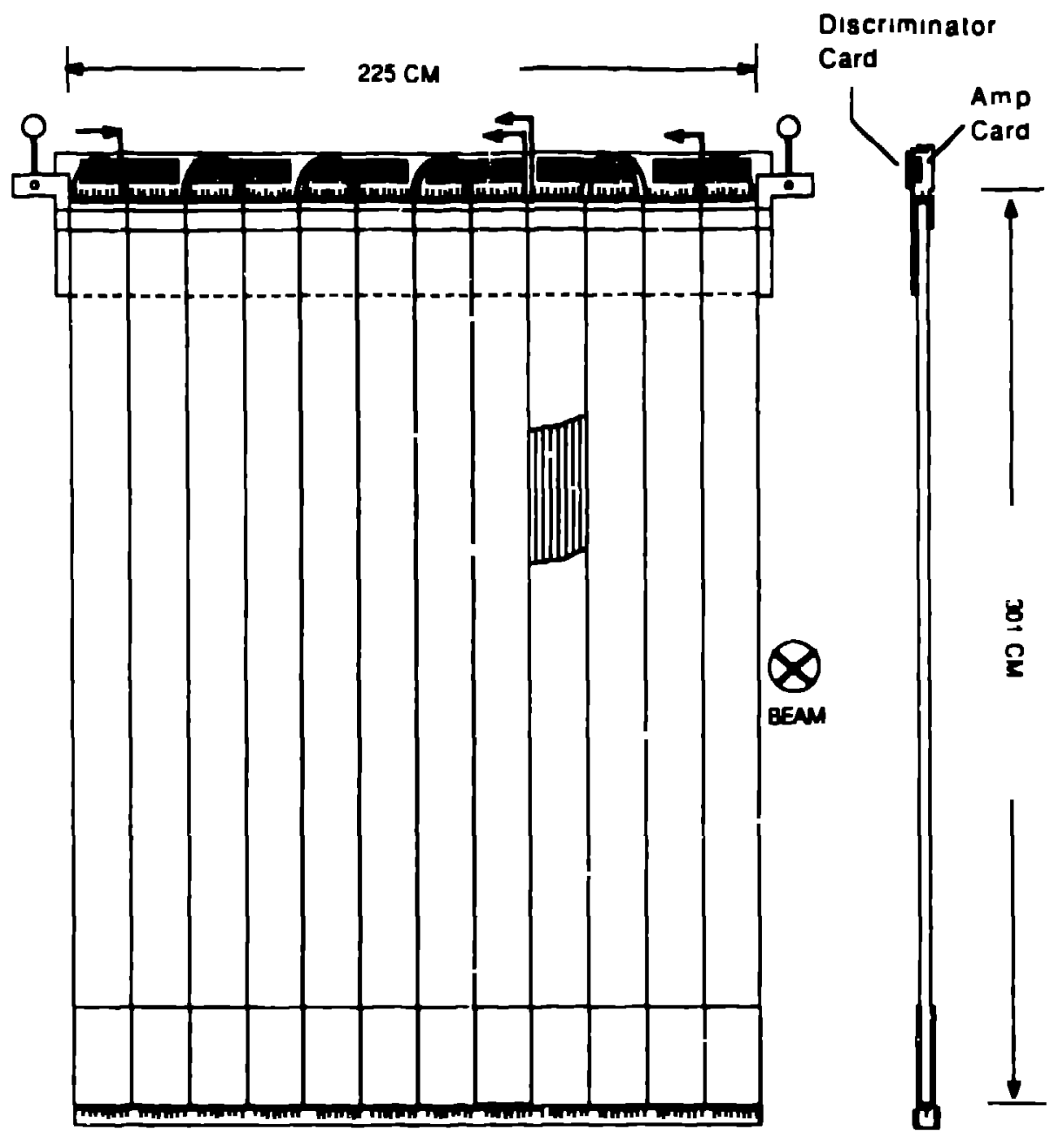

X.PUANE

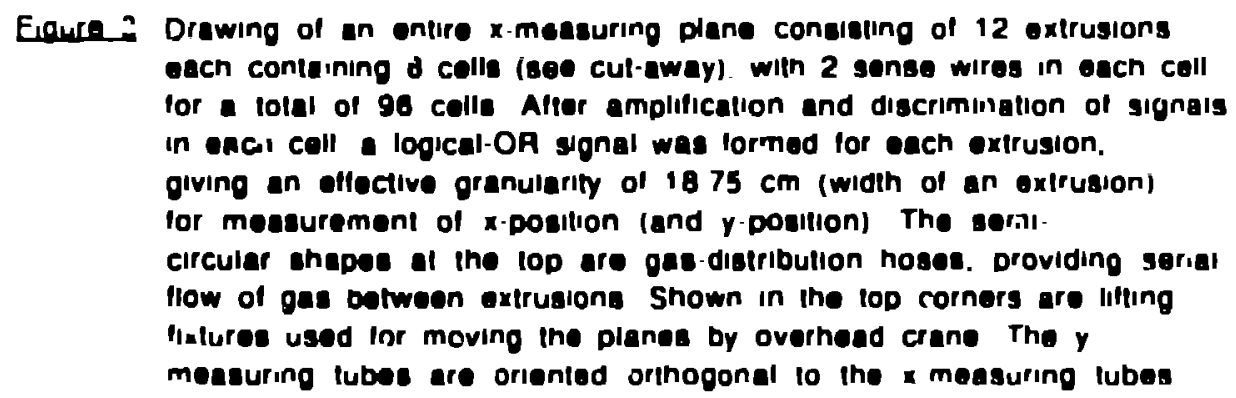

Pulae frum the proporional tute wires were processed by lwo circuits. first a pre amplifier stage. then an amplifier discriminator slage. shown in I-pure 4 the wires were cupacilively cuupled $(22(x) \mathrm{pf})$ to the input lape at the pre anplifier curcuit Pre amplificdion was

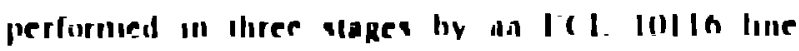
recerer. which hav a gath of 1 lor each intpul
When both the differenial mutpu's are used. the effeclive gain is eight The three si-nes provitued i loul effective gain of 128 for nomunal $2 \mathrm{mV}$ inpul rignals ciain was not specified by the manufacturer for these line recieivers. (1). durillg tesming. chips with gain varialinis prealer thall - jow were discarded lest pulves uere injerted ill, the circull hy a copper irace runulnk 


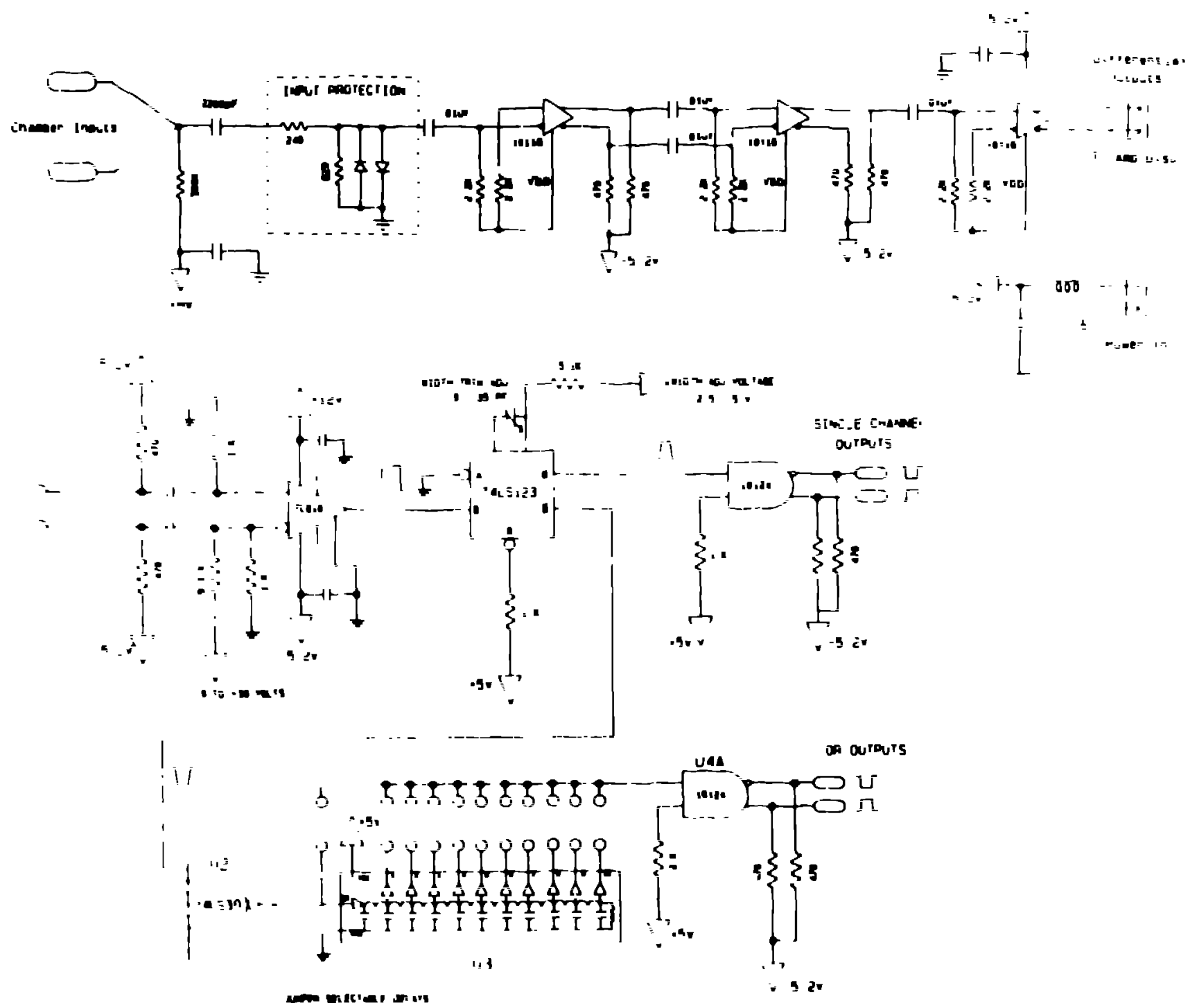

Eugure 4. Circull diagrams for pre-amplifier z. u amplifier-discriminstor stages of the rangefinder electronics The circult :' the top of the figure is the pre-amplifier siage, using three 10116 line-inveis as amplifiers to obiain a gan of 128. The amplified signals were discnminated by the TL810 voliage comparator. which triggered a 14LS123 monostable multivibrator with adjustable ouiput widih set $10160 \mathrm{~ns}$. The sectinn labelled "jumper seleciable delays' was not implemenied

underneath all the inpul traces. Pulse discriminaion was performed by capacilively coupling the pre amplifier outputs to the inpul if - Ml.kio comparator The negalive input of the comparalor was hased posilively. so that only differential inpul signals greater than the bias whlage fired the conpuralur the leading edge of the comparator oulput inggered a monosiable multivibrator with ouput wilth adjusted it in() 19 The monosidhle multivibitor outputs for all $\mathrm{A}$ cells in an extrusion were combined io prosluce a logical OR agnal. which was converted (I) a differenial ECL signal. and driven wer I ineiers of iwisted-par cable and 10 meiers of Ansley cable to the countung house. where sghals were Iulched and read out

The primary inuon idenufying element .I the trigger level was the murn hodossople I his cintilatur instrunient had a narrow hit

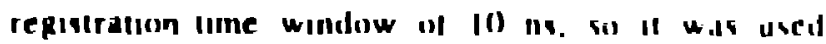
I, establish the liming of the rallgetinder rediliut

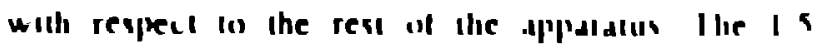


$\mu A$ threshold and i60-ns length of the

discriminated rangefinder pulses was set to achieve 95\% efficiency for track-associated hits.

The net efficiency for each rangefinder gap was measured by counting missing hits in otherwise well-defined tracks. An overall efficiency of $94 \%$ was achieved for the nominal running conditions of $3 \times 10^{12}$ protons per pulse striking the production target ( 3 Tera-protons, or $3 \mathrm{Tp}$ ). A test at $8 \mathrm{Tp}$ rate (our ultimate running condition) was also performed yielding the same efficiency results. The nominal running condition of $3 \mathrm{Tp}$ per spill corresponded to about $10^{6}$ tracks per second entering the rangefinder in the 1.5 to $7.0 \mathrm{GeV} / \mathrm{c}$ momentum range. Rates were higher close to the centerline of the beam. There has teen no evidence of wire aging; for the approximately 1000 hour beam exposure. integrated current per wire was estimated to be about $2 \times 10^{-4}$ Coulombs/cm. Approximately $84.6 \%$ of the tracks were fully contained in the rangefinder volume, with $6.6 \%$ exiting the rear, and the remaining $8.8 \%$ ending at side surfaces. Of these $8.8 \%$ exiting the sides, $7.0 \%$ ended at the interior surface (adjacent to the neutral beam) of the detector, and Monte Carlo studies indicated that the track-finding algorithm picked-up spurious tracks originating near the interior edge. Spurious tracks were produced by kaons decaying near the rangefinder, and neutrons interacting in the absorber material. Using well-identified muon tracks from the copious decay $K_{L}^{0} \rightarrow \pi \mu v$, the rangefinder muon identification efficiency was measured to be $95 \%$, for tracks penetrating at least $60 \%$ of the depth expected from their spectrometer-derived inomentum. Momentum resolution was measured offline for tracks by comparing the actual stopping position to that expected from spectrometer-derived momentum A typical resolution curve is shown in Figure 5 . with approximately $87 \%$ of the muons stopping within \pm 1 instrumented gap of the expected range in the marble stack, corresponding to $\pm 10 \%$ resolution. The expected range was derived from a look-up lable generated in a Monte Carlo model of the range stack, which included the effects of multiple scallering.

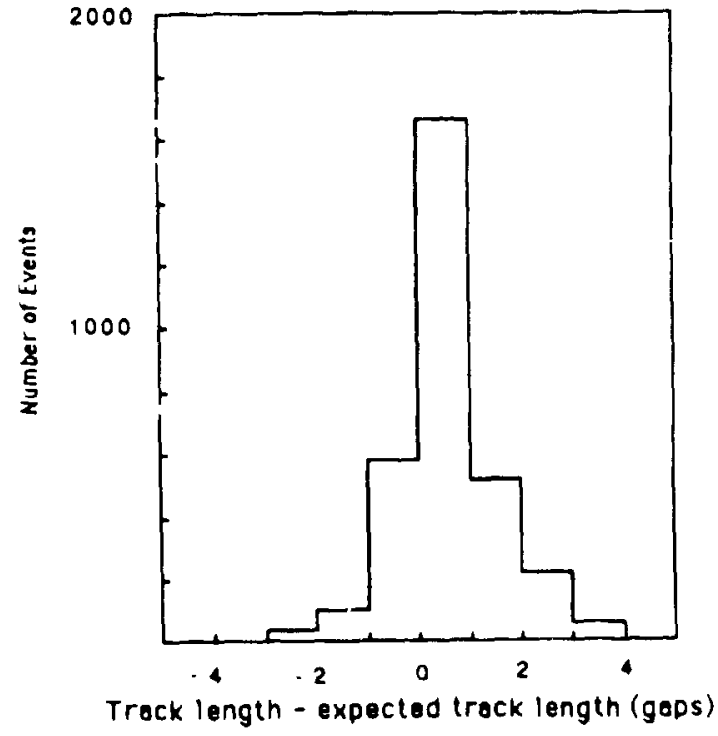

Figure 5 Momentum resolution of the muon rangefinder. This is a histogram produced by subtracting the track length predicted from the spectrometer-derived momentum from the penetration depth found for muon tracks in the rangefinder Each instrumented gap corresponded to about a $10 \%$ momentum difference compared to the neighboring gap. About 878 of the muons stopped within \pm 1 gap of the predicted range, yielding $\pm 10 \%$ momentum resolution

An event display for a typical $\mathrm{K}_{\mathrm{L}}^{\mathrm{O}} \rightarrow \mathrm{H}^{+} \mu^{-}$ decay $(6)$, a rare process with a branching ratio equal to $9.1 \times 10^{-9}$, is shown in Figure 6 . For this event, there is good agreement between the spectrometer-derived momentum and that given by the depth of penetration of both tracks into the muon-range stack. 


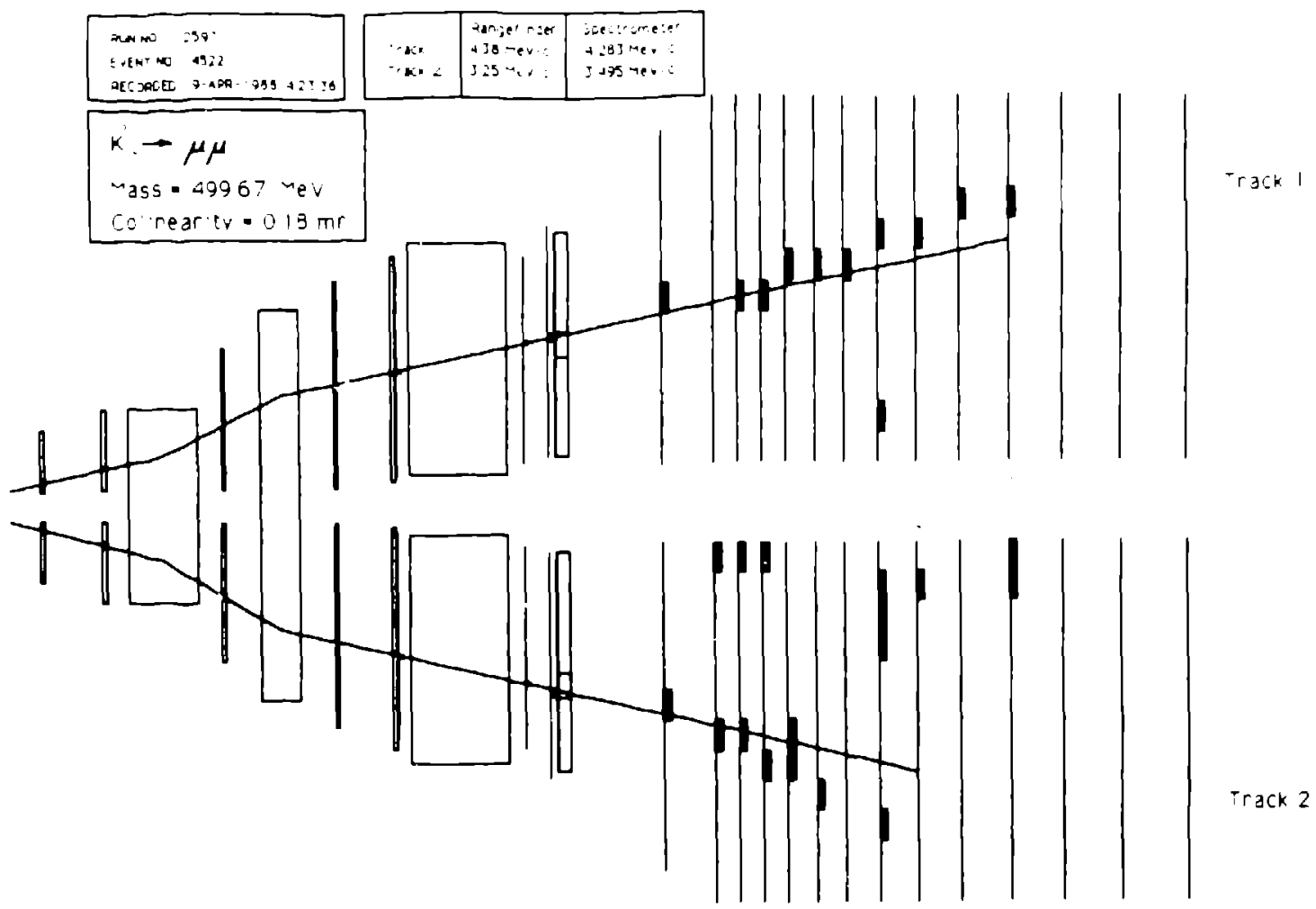

Eigure 6: An event display for a typical $\mathrm{K}_{\mathrm{L}}^{0} \rightarrow \mu^{+} \mu^{-}$decay $(6)$, a rare process with a branching ratio equal to $9.1 \times 10^{-9}$. For this event, there is good agreement between the spectrometer-derived momentum and that given by the depth of penetration of both tracks into the muon-range stack. The lines drawn to indicate the rracks corresponc to a straight-line projection from the tracks found in the spectrometer drift chamters. The asterisks shown between the two rangefinder arms nark the end of the track found by the track-finding algorithm. The inaximum depth in $x$ - and $y$-views is taken as the end of the track. The $x$-view is shown in this

- figure, and in the $y$-view the track on the beam-right side was one gap longer.

\section{References}

(a) Present address: Physics Department, Brookhaven National Laborarory, Upton, New York 11973

(i) Present address: EG\&G Inc., Energy Measurements, Suillend, Maryland 20746.

(c) Present address: CEBAF, Newport News, Virginia.

(d) Present address: MCI Telecommunications Corp., 8283 Greensboro Drive, McLean, Virginia 22102.

(1) R. D. Cousins el al, Phys. Rev. D to be published Nov. I. 1988.

(2) C. J. Kenney ef al, "Use of gas proportional abes in a Muon polarimeter," Proceedings of this Symposium
(3) D. M. Lee. J. R. Bilskie, and G. H. Sanders, "The response of drift tubes to variations in wire dianteter and gas fillings." Nucl. Instrum. Methods A 256329 (1987). LA-UR 86-2773.

(4) M. Alac, "Wire chamber aging," Pro eedings of the Workshop on Radiation Damage to Wire Chanibers, LBL (1986). LBL-21170.

(5) Y. Hoshi et al., "A simple method for measuring wire tension in drift tubes," Nucl. Instrum. Methods A:36, 82 (1985).

(6) W. C. Carithers et al., Phys. Rev, Lelt. 30. 1336 (1973); W. C. Carithers ef al. Phys. Ruv. Lett. 11. 1025 (1973); Y. Fukushima et al. Phys. Rev. Lett. 36. 348 (1976); M. J. Shochel et ol. Phys. Rev. D 19. 1965 (1979); H. B. Greenlee el al. Phys. Rev. Lell. 60,893 (1988). 